\title{
Epidemiology of Intrauterine Fetal Deaths: A Study In Tertiary Referral Centre In Uttarakhand
}

\author{
Dr Anjali Choudhary ${ }^{1}$, Dr Vineeta Gupta ${ }^{2}$ \\ ${ }^{I}$ (Assistant Professor, Department of OBGYN, SGRRIM\&HS, Dehradun, Uttarakhand, India) \\ ${ }^{2}$ (Professor, Department of OBGYN, SGRRIM\&HS, Dehradun, Uttarakhand, India)
}

\begin{abstract}
Background: Intrauterine fetal death (IUFD) and still birth is a tragic event for the parents and a great cause of stress for the caregiver. Objective: Present study was conducted to understand the prevalence, socio-epidemiological and etiological factors of intrauterine fetal death [IUFD] and stillbirths. Materials and Methods: Pregnancies diagnosed with IUFD and the cases of stillbirths were studied retrospectively. Ante partum and intra partum events leading to fetal demise were recorded, socio-demographic and clinical characters were noted. Result: During the study period there were 2165 deliveries out of which 105 were IUFDs and stillbirths. The incidence of prenatal loss was 49 per 1000 live births. Conclusion: Despite advances in diagnostic and therapeutic modalities the rate of still birth is unacceptably high. Socio-cultural background, poverty, illiteracy, lack of adequate antenatal care and inaccessible health care are some of the reasons that predispose women to IUFD and stillbirth. Majority of fetal wastage can be prevented with universal and improved antenatal care.
\end{abstract}

Keywords: Intrauterine fetal death, stillbirth, incidence, epidemiology.

\section{BACKGROUND}

Intrauterine fetal death and still birth is a tragic event for the parents and a great cause of stress for the caregiver. Defined as the death of fetus more than 24 weeks of gestation and weighing more than 500 grams IUFD is major cause of pregnancy wastage. WHO definition of still birth is 'fetal death in late pregnancy' [3]. The gestational age at which intrauterine fetal demise is considered a still birth varies from county to country. Some countries count demise at 16 weeks as IUFD while others consider fetal demise as late as 28 weeks as IUFD. The Perinatal Mortality Surveillance Report [CEMACE, 2011] defines stillbirth as 'a baby delivered without signs of life after 24 completed weeks of pregnancy'. ACOG refers to IUFD as the demise occurring at or later than 20weeks. In a recent RCPI [Recent clinical practice investigation guideline], stillbirth is taken as a baby delivered without signs of life from 24 weeks gestation and IUFD is taken to refer to death in utero after 24 weeks gestation [3]. IUFD and intra-partum fetal deaths together constitute a large portion of perinatal mortality. Ante-partum fetal death contributes to about two thirds of prenatal mortality [5]. Prevalence of perinatal deaths in a society is the direct indicator of the quality of antenatal care in the country [5]. The prevalence of IUFD has been reduced to a minimum unavoidable rate in developed countries; however it still remains very high in underdeveloped and developing countries. Prevalence of IUFD and stillbirth is expressed as number of fetal deaths per 1000 live births. Range of incidence varies in different countries, ranging from five in 1000 births in high income countries [4] and 36 in 1000 births in developing countries [2]. Rate of perinatal deaths in India is 32 per 1000 live births,[35 per 1000 live births in rural areas and 22 per 1000 live births in Urban areas], still birth rates in India is 9 per thousand births,[9:1000 births in rural India and 8in 1000 births urban India], according to the Indian census of 2006 [1].

Although three million stillbirths occur annually worldwide, almost as high as post natal deaths, they have not been addressed as much. The developing countries in Asia and sub Saharan Africa together constitute $70 \%$ of the world's stillbirth burden [2]. Lack of prenatal care, inaccessible or limited health care facility is the major factor responsible for high peri-natal deaths in these regions. Many times these mortalities are due to preventable causes. Multitudes of factors are recognized as the causes of IUFD and stillbirth. There are many classifications of etiology of perinatal deaths [7]. Tulip, extended Wigglesworth, modified Aberdeen, Re Co De, PSANZ-PDC are some classifications in current use. Aberdeen and Wigglesworth use maternal and fetal factors to classify causes of fetal death while PSANZ-PDC and Tulip use maternal, fetal and placental factors $[6,11$, and 12]. Re Co De system classifies fetal death depending upon "Relevant condition at Death." Despite the method of categorizing the causative factors, majority of the intrauterine deaths remain unexplained. Classifying fetal deaths helps in identifying the probable etiology and the series of events that eventually led to fetal demise. It also helps in formulating prevention policies and protocols. Identification of cause of IUFD will be helpful in counseling and consoling the grieving parents [11]. Bereavement counseling in the event of death of a viable child is the most difficult job for the obstetrician. Parents need to have closure with the tragedy and alley their fear regarding future pregnancies. 


\section{OBJECTIVE}

Present study was conducted to understand the prevalence, socio-epidemiological and etiological factors of IUFD and stillbirths in a retrospective analysis of 105 cases.

\section{MATERIAL AND METHODS}

A total of 105 cases of IUFD and stillbirths over a period of two years were studied retrospectively, in the department of obstetrics and gynecology of a tertiary care hospital in Dehradun, India. Diagnosed cases of pregnancies with IUFD and stillbirths were included. Criteria for diagnosis were absent fetal heart sounds and an ultrasonographic confirmation. Ante partum and intra partum events leading to fetal demise were noted. Data collected to note the following parameters.

Socio-demographic factors: Women's age, religion, parity, education level, socio-economic status, level of antenatal care, immunization, and Iron and calcium intake noted.

Clinical parameters: Gestational age at the time of diagnosis, obstetric history, past and present medical history, history of pregnancy related and aggravated conditions noted.

Complete investigations like hemoglobin levels, blood group, urine examination, HIV, HbsAg, VDRL, blood sugar, Thyroid profile, LFT, KFT was noted. Special investigations were done relevant to the case.

Recorded data analyzed to identify probable cause of IUFD.

\section{RESULTS}

During the study period there were 2164 deliveries out of which 105 were stillbirths. The incidence of stillbirths in our study was 49 per 1000 live births. Out of which 56 were fresh and 49 were macerated stillbirths. There were 58 male babies and 47 female babies. Out of the 94 cases $10.47 \%$ were booked. Majority of women were primigravida (44.6\%). Most cases of IUFD were diagnosed between 31 to 40 weeks of pregnancy. Hypertensive disorder was found to be complicating $28.7 \%$ pregnancies, and $4.2 \%$ women were diabetic. A total of $17.2 \%$ cases presented with Ante partum hemorrhage out of which $3.9 \%$ were placenta previa, and $11.7 \%$ placental abruption. Mild anemia was found in $19.4 \%$ cases, moderate in $6.3 \%$ cases and $15.9 \%$ were severely anemic. There was one case of road traffic accident. Severe IUGR was found to be responsible for the death of $8.5 \%$ babies, $11.5 \%$ fetuses had congenital anomalies. Maternal infections were found to be complicating eight pregnancies out of which there were two cases of jaundice [infective hepatitis] five cases of clinically proven malaria and one case of pneumonia. All the cases of malaria were clustered in the month of August. There were 19.5\% women where no causative factor was found for intrauterine fetal demise. Further investigation -including an autopsy- was ordered but the patients refused.

Unbooked -94 women (89.53\%) Booked-11 women (10.47\%) Total-105 women

Table - 1: Demographic Parameters

\begin{tabular}{|l|c|l|c|l|c|}
\hline Age group (years) & Number (\%) & Parity & Number (\%) & G.A (in weeks) & Number (\%) \\
\hline $16-20$ & $5(4.76)$ & G1 & $47(44.76)$ & $24-30$ & $29(27.62)$ \\
\hline $21-25$ & $48(45.71)$ & G2 & $23(21.90)$ & $31-35$ & $35(33.33)$ \\
\hline $26-30$ & $38(36.19)$ & G3 & $16(15.24)$ & $36-40$ & $29(27.62)$ \\
\hline $31-35$ & $13(12.38)$ & G4 & $14(13.33)$ & $40+$ & $12(11.43)$ \\
\hline $40-$ & $1(0.95)$ & G5 & $5(4.76)$ & & \\
\hline
\end{tabular}

Table - 2: Key Clinical Risk Factors

\begin{tabular}{|c|c|c|c|c|c|c|}
\hline Key Factors & & Sub Factors & Number(\%) & Additional Risk in Maternal & Additional Risk in Fetal & Additional Risk in Placental \\
\hline \multirow{3}{*}{ Maternal } & 1 & PIH and complications & $30(28.75)$ & 3 & 0 & 10 \\
\hline & 3 & Medical disorders & $6(5.71)$ & 1 & $\mathbf{0}$ & $\mathbf{0}$ \\
\hline & 4 & Infections & $8(7.62)$ & 0 & 1 & 0 \\
\hline \multirow[b]{3}{*}{ Fetal } & 1 & Congenital anomalies & $11(10.48)$ & $\mathbf{0}$ & $\mathbf{0}$ & $\mathbf{0}$ \\
\hline & 2 & Rh isoimmunization & $1(0.95)$ & 0 & 0 & 0 \\
\hline & 3 & Non immune hydrops & $2(1.90)$ & 0 & 0 & 0 \\
\hline \multirow{5}{*}{ Placental } & 1 & Placenta previa & $4(3.81)$ & 3 & 0 & 0 \\
\hline & 2 & Accidental hemorrhage & $11(10.48)$ & 7 & $\mathbf{0}$ & $\mathbf{0}$ \\
\hline & 3 & IUGR & $8(7.62)$ & 5 & 1 & $\mathbf{0}$ \\
\hline & 4 & Cord accidents & $2(1.90)$ & 0 & 0 & 0 \\
\hline & 5 & Postdatism & $4(3.81)$ & 0 & 0 & 0 \\
\hline Others & 1 & Road Traffic Accident & $1(0.95)$ & $\mathbf{0}$ & $\mathbf{0}$ & $\begin{array}{ll}0 \\
0\end{array}$ \\
\hline Unexplained & 1 & No risk factor & $20(19.05)$ & $\mathbf{0}$ & $\mathbf{0}$ & $\mathbf{0}$ \\
\hline
\end{tabular}

* In Many cases there were more than one risk factor 


\section{DISCUSSION}

Death of a viable fetus is a distress to the family and the obstetrician. Despite advances in medical science, diagnostic and therapeutic modalities, pregnancy wastage still occurs, at an unacceptably high rate. Although the perinatal mortality has reduced over last few decades the fetal deaths still remain high. [3] Present study observed 49 stillbirths per 1000 live births per 1000 live births, a rate higher than the national average of 38 stillbirths per 1000 LB.]. Our facility is tertiary referral centre and many women are referred for further management after IUFD has already been diagnosed. Rate of stillbirths vary greatly in different studies and regions. A study from Faridkot India, quotes a still birth rate of 125 per 1000 live births, another similar study from Saudi Arabia states a rate of 10 per 1000 births [13, 9]. There is a need for retrospection and introspection to figure out probable causes of fetal deaths and device strategies to reduce the burden. Although chromosomal abnormalities and congenital malformations are unavoidable, routine screening and selective termination of pregnancies would reduce these deaths. In our study $11.5 \%$ cases were due to congenital malformations. Other causes of fetal demise like PIH, Diabetes, IUGR, placental abruption, maternal infection, post-datism, Rh isoimmunozation are preventable causes of IUFD. Proper antenatal care, recognition of risk factors appropriate management, judiciously timed delivery, intra partum monitoring and timely intervention has reduced the incidence deaths resulting from these factors.

Over the years the causative factors responsible for IUFD have changed. There was an observation that not only the incidence of stillbirth reducing in developed countries, but the pattern of etiologies are also changing [6].Some causes incriminated in fetal wastage like syphilis, $\mathrm{Rh}$ isoimmunization thirty years ago, are no longer significant [4]. Since the introduction of $\mathrm{Rh}$ immune prophylaxis, still births resulting from $\mathrm{Rh}$ isoimmunization have largely been reduced, accounting for less than $1 \%$. Still births occurring during labor as a result of fetal hypoxia, are lesser due to electronic fetal monitoring [<1: 10,1000births][4] However newer entities like thrombophillias, intrahepatic cholestasis of pregnancy have only recently been recognized as significant contributor to prenatal mortality. Despite extensive research and treatment modalities available many of the stillbirths remain unexplained [3]. The percentage of unexplained fetal demise has stayed constant over the years. It was observed in the present study that $19.5 \%$ fetal deaths were in this category. Neetu singh et al found 33\% unexplained fetal deaths in their study of 296 cases of IUFD [10]. These deaths occur in late pregnancies and sometimes even in women with regular antenatal care. Lamia Shaban et al in their study of 157 cases of IUFD observed $28 \%$ cases without a probable cause [9]. Death of a well grown viable fetus is tragic enough but not knowing the cause of it can be distressing

It is a well established fact that adequate prenatal care is associated with better pregnancy outcome [5]. However implementation of universal prenatal care is dependent on lot of factors like availability of health care facilities, skilled personnel, infrastructure and transport. Government of Uttarakhand with the help of USAID has adapted Health and Population Policy to upgrade health care in the area since 2002.The policy specified certain goals to achieve by year 2010.Achieving fertility rate of 2.1 children per woman, increasing contraceptive use, reduce maternal and infant mortality, implementing antenatal care and promoting institutional deliveries were few of the goals [14]. Since inception of the policy prenatal care increased from $20 \%$ to $45 \%$ and institutional deliveries increased from $21 \%$ to $36 \%$ from year 1989 to 2006.Despite these efforts a lot more needs to be done to bring down IUFD rate to a minimum acceptable figure.

Many women in remote rural areas of Uttarakhand still have no access to expert care, no transport to nearest hospital and low finances to afford healthcare and medical help. Poverty is wide spread, earning livelihood is difficult, and women suffer lot of hard ships due to mountainous regions and unpredictable weather. Most of the women with IUFD in present study were unbooked or had irregular antenatal care $(89.5 \%)$.

Uttarakhand is hilly region with difficult terrain and inaccessible areas. Natural disasters like excessive rains, floods and landslides are fairly frequent, causing damage to infrastructure, roads and transport. Women in these areas begin their pregnancies at an earlier age, with lower nutritional and iron reserves; have too many pregnancies, too often. Due to lack knowledge or inaccessibility to healthcare facility they receive little or no antenatal care. Many women are still delivered at home by untrained dais, in case of difficult labor, the transport to the nearest hospital is fraught with logistic problems and by the time they reach a facility where a definitive management can be given they come in an advanced state of PIH, obstructed labor, cord accidents, APH etc. when salvaging the fetus is difficult. In a study by Jahanfer et al it was found that women from rural and inaccessible areas women are more prone to perinatal fetal loss than the urban women [6]. In recent times cesarean section rates have increased markedly thereby leading to increase in post cesarean pregnancies. Short interval since the cesarean birth, late admission to labor rooms, or late arrival from distant areas are the cases in which scar dehiscence and rupture uterus causes fetal death, however in our study there were only two such cases.

Major causes of fetal demise in our study were hypertensive disorders of pregnancy, IUGR, APH, congenital anomalies. In a large Meta analysis for the cause of IUFD Ruth frets found at least fifteen causes accounting for stillbirths. According to her observations unexplained stillbirths and Severe IUGR are two 
categories that contribute to most fetal losses. [4]. Al Kadri etal found that women that did not receive ANC are at $70 \%$ risk of IUFD. It is 25 fold higher in women with placental abruption, tenfold higher in Babies with IUGR and three fold higher with PIH [7].According to Kotweg etal the single most important cause for IUFD was growth restriction, emphasizing the importance of placental role in optimal fetal growth [8].

Socio- demographic factors also need to be considered as predisposing factor for prenatal deaths, especially in developing country like India, where many people live in rural areas. Illiteracy, early marriages, teenage pregnancies, unregulated reproduction, low socio-economic states, poor nutrition, lack of health education and antenatal care all conspire against the women's health and predispose her to IUFD and still birth[7]. Lack of antenatal care is directly related to the socioeconomic and educational level of women. Health education toward stressing the importance of antenatal care, ante partum screening for congenital malformations and selective pregnancy terminations, patient compliance and vigilant monitoring will reduce a number of preventable fetal deaths[8].

\section{CONCLUSION}

Nothing is as sad and depressing as intrauterine death of a fetus for both parents and the obstetrician. Congenital fetal malformations and anuploidies are unavoidable but IUFD due to these causes can be prevented by routine prenatal screening. Hypertensive disorders, Diabetes ante partum hemorrhage, IUGR, maternal infections are the common factors causing fetal demise which are preventable. Despite advances in diagnostic and therapeutic modalities a large number of fetal deaths remain unexplained, even with proper antenatal care. Socio-cultural background, poverty, illiteracy, unawareness and inaccessible health care are some of the reasons that predispose women to IUFD and stillbirth. Majority of fetal wastage can be prevented with health education, universal and improved antenatal care.

\section{REFERENCES}

[1] Estimates of mortality indicators-Census of India website-vital statistics Chapter 4 Pg 81, statement 512010

[2] Cousens S, Blencowe H, Stanton C, et al National, regional, and worldwide estimates of stillbirth rates in 2009 with trends since 1995: a systematic analysis. Lancet 2011; 377: 1319-30.

[3] CLINICAL PRACTICE GUIDELINE: INVESTIGATION AND MANAGEMENT OF LATE FETAL INTRAUTERINE Death and stillbirth, Institute of obstetrician and gynecologists, Royal College of physicians Ireland, and Directorate of strategies and clinical programmed, health service executive. Version 1.0, guideline no. 4 October 2011-revised 2013

[4] Ruth C. Frets, Etiology and prevention of still birth, American journal of obstetrics and gynecology (2005) 193, 1923-35.

[5] Richardus, Jan H., Graafmans, Wilco C. Verloove-Vanorick, S. Pauline. Mackenbach, Johan P., The perinatal mortality Rate as an Indicator of Quality of Care in international comparisons. Medical Care, January 1998-vol 36 Issue 1-pp 54-66.

[6] Jahanfar Sh, Ghiyasi P,Haghani H Sh ,Risk factors related to intra uterine fetal death in Iran ,A case control study.Shiraz E-Medical journal ,Vol.6,3,\&4 July and October 2005.

[7] Al Kadri, Hanan Tamim, Hani, Factors contributing to intra uterine fetal death, Archives of obstetrics and gynecology, Nov.2012, vol., 286, Issue 5, P 1109

[8] Kotweg F.J., GordjinS,J,Timmer A.Holm J P.,RaviseJM, ErwichhJJ,A placental cause of Intrauterine Fetal Death depends on the perinatal mortality classification used,Placenta,2008,Jan 29(1):71-80PUB 2007oct 25

[9] Lamia A Shaaban A Al Saleh ,Buthina M Alwafi, Rajaa M Al Raddi, Associated risk factors with ante-partum intra-uterine fetal death.Saudi Medical journal 02/ 2006 (1)76-9.source pubmed

[10] Neetu Singh, Kiran Pandey, Neena Gupta, A K Arya, Charu Pratap, Reshika Naik. A retrospective study of 296 cases of intra uterine fetal deaths at a tertiary care centre . Int J Reprod Contracept Obstet Gynecol. 2013 Jun;2(2):141-146

[11] ILu JR, Mccowan L A comparison of the perinatal society of Australia and Newzealand -perinatal death classification systems and relevant condition at death stillbirth classification systems, Aust NZ Obstet gynecolo. 2009 oct: 49 (5) doi: 10 .1111/j. 1479-828X. 2009, 01066.x.

[12] Goyal Lajya,D Parveen Rajori, Verbal Autopasy of 115 cases of Intrauterine fatal Death .Indian Journal of Public health research and Developement,Vol.4 Issue 1. 2013, Pg 147-152.

[13] INFORMING EQUITABLE HEALTH POLICY REFORM: Policy Implementation Assessment Inspires Action in Uttarakhand, India MAY 2010. Referred website on Sep 21, 2013 http://www.healthpolicyinitiative.com/Publications/Documents/1156 1_Uttarakhand_Final_Brief_FINAL_5 31_10_acc.pdf 